\title{
The sun in the tank? Possibilities and limitations of MtG technology from the chemical perspective
}

Prof. Dr. Martin Bertau, Co-Authors: Dr. Ludolf Plass, Dr. Konstantin Räuchle, Michael Kraft, all Institute of Technical Chemistry, TU Bergakademie Freiberg

Zum Zeitpunkt der Drucklegung lagen diese Unterlagen noch nicht vor. Wir bitten um Verständnis. 